$$
\text { CONF-9609298-1 }
$$

\title{
PORE LEVEL IMAGING OF FLUID TRANSPORT USING SYNCHROTRON X-RAY MICROTOMOGRAPHY
}

\author{
M. E. Coles and R. D. Hazlett \\ Mobil Exploration and Producing Technical Center . \\ Dallas, Texas 75381-9047 \\ P. Spanne \\ European Synchrotron Facility \\ F-38043 Grenoble Cedex, France \\ W. E. Soll \\ Los Alamos National Laboratory \\ Los Alamos, New Mexico 87545 \\ E. L. Muegge \\ Mobil Exploration and Producing Technical Center \\ Dallas, Texas 75381-9047
}

K. W. Jones

Brookhaven National Laboratory

Upton, New York 11973

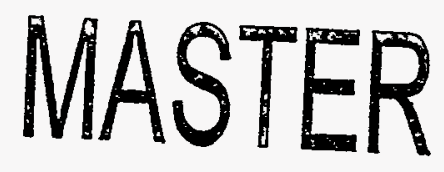

Presented at

1996 Annual Technical Conference of the Society of Core Analysts

Montpellier, France

September 8-10, 1996

By acceptance of this article, the publisher and/or recipient acknowledges the US Government's right to retain a nonexclusive, royaltyfree license in and to any copyright covering this paper. 


\section{DISCLAIMER}

This report was prepared as an account of work sponsored by an agency of the United States Government. Neither the United States Government nor any agency thereof, nor any of their employees, makes any warranty, express or implied, or assumes any legal liability or responsibility for the accuracy, completeness, or usefulness of any information, apparatus, product, or process disclosed, or represents that its use would not infringe privately owned rights. Reference herein to any specific commercial product, process, or service by trade name, trademark, manufacturer, or otherwise does not necessarily constitute or imply its endorsement, recommendation, or favoring by the United States Government or any agency thereof. The views and opinions of authors expressed herein do not necessarily state or reflect those of the United States Government or any agency thereof. 


\section{DISCLAIMER}

Portions of this document may be illegible in electronic image products. Images are produced from the best available original document. 


\title{
Pore Level Imaging of Fluid Transport using Synchrotron X-Ray Microtomography by
}

\author{
M. E. Coles ${ }^{1}$, R. D. Hazlett ${ }^{1}$, P. Spanne ${ }^{2}$, W. E. Soll ${ }^{3}$, E. L. Muegge ${ }^{1}$ and K. W. Jones ${ }^{4}$
}

\begin{abstract}
Recently developed high resolution computed microtomography (CMT) using synchrotron X-ray sources is analogous to conventional medical CT scanning and provides the ability to obtain threedimensional images of specimens with a spatial resolution on the order of micrometers. Application of this technique to the study of core samples has previously been shown to provide excellent twoand three- dimensional high resolution descriptions of pore structure and mineral distributions of core material. Recently, computed microtomographic endpoint saturation images of a fluid filled sandstone core sample were obtained using a microtomographic apparatus and a high energy X-ray beam produced by a superconducting wiggler at the National Synchrotron Light Source at Brookhaven National Laboratory. Images of a $6 \mathrm{~mm}$ subsection of the one inch diameter core sample were obtained prior and subsequent to flooding to residual oil. Both oil and brine phases were observable within the imaged rock matrix. The rock matrix image data was used as input to a fluid transport simulator and the results compared with the end point saturation images and data. These high resolution images of the fluid filled pore space have not been previously available to researchers and will provide valuable insight to fluid flow, and provide data as input into and validation of high resolution porous media flow simulators, such as percolation-network and Lattice Boltzmann models.
\end{abstract}

\section{Introduction}

Computed X-ray tomography is often utilized to characterize structure and fluid distributions within reservoir core material systems. Generally, medical computed tomography (CT) scanners have been employed because of their availability and relative ease of use. Of interest lately has been the acquisition of three-dimensional, high resolution description of rock structure and pore level characterization for the modeling of multiphase transport processes. Medical CT scanners are generally limited to no better than 0.25 by 0.25 by $1.5 \mathrm{~mm}^{3}$ in volume resolution and therefore cannot provide information sufficient to define the three-dimensional pore structure of reservoir rock.

Recently developed computed microtomography (CMT) is analogous to medical X-ray absorption CT scanning and produces images with much higher spatial resolution ${ }^{1}$. Synchrotron $\mathrm{X}$ rays, generated in a storage ring for relativistic electrons, are often employed for microtomography. With synchrotron $\mathrm{X}$-ray CMT, three-dimensional maps of linear X-ray attenuation coefficients inside small samples can be obtained with about $1 \%$ accuracy and resolution approaching $1 \mu \mathrm{m}$.

Synchrotron $\mathrm{X}$ rays have been used to generate microtomograms of biological samples, thermal spray coatings, coal and heterogeneous catalysts. ${ }^{2-6}$ Recently, there has been interest in using synchrotron $\mathrm{X}$-ray CMT for characterization of porous media for geological applications.7-8 Advantages include very high spatial resolution (reported 5 micrometers), narrow energy band (fewer artifacts) and tunability (increased sensitivity and mineralogical information).

Application of this technique to the study of core samples has previously been shown to provide excellent two- and three- dimensional high resolution descriptions of pore structure and mineral distributions of core material ${ }^{8}$. Microtomographic images of real rock can serve as boundary conditions for rigorous fluid flow modeling9-14. With microtomographic data, opportunities therefore exist to significantly impact the description and understanding of fluid transport properties within core material systems.

1. Mobil Exploration and Producing Technical Center, P. O. Box 819047, Dallas, Texas, 75381-9047

2. European Synchrotron Facility, F-38043 Grenoble Cedex, France.

3. Los Alamos National Laboratory, Los Alamos, NM 87545.

4. Brookhaven National Laboratory, Upton, NY 11973. 
Recently, computed microtomographic endpoint saturation images of a fluid filled sandstone core sample were obtained using a microtomographic apparatus and a high energy X-ray beam produced by a superconducting wiggler at the National Synchrotron Light Source (NSLS) at Brookhaven National Laboratory (BNL). The rock matrix image data was used as input to a high-resolution, multiphase fluid flow simulator and the results compared with the end point saturation images and data. This paper presents an integration of novel experimental and computational techniques that together provide a tool to expand understanding of, and ability to model, reservoir flow processes. In the first section we will discuss the CMT measurement process. We will follow that with a description of the coreflood experimental setup and results and a description of two numerical simulation methods. After that we will compare the experimental and simulation results and summarize our findings.

\section{Computed Microtomography Theory and Measurement Process}

As with medical X-ray CT scanning, CMT data collection for a tomographic slice through a sample is performed by measuring the relative number of transmitted $X$ rays for a large number of $X$-ray paths with different radial and azimuthal coordinates. The sampling can be performed either by using a single pencil beam and detector (called first generation scanning), or by using a wide X-ray beam and an array of detectors with high spatial resolution capability. Use of detector arrays allows considerably faster CMT, but at some loss of spatial resolution. First generation scanning was employed for the work discussed here. Subsequent development and application of a high resolution detector array has been accomplished and is expected to be the preferred method of obtaining data in future experiments ${ }^{15}$.

After CT data collection, the line integrals of the linear attenuation coefficients are obtained by taking the logarithm of the reciprocal of the relative number of transmitted photons. This is input to a reconstruction algorithm ${ }^{16}$ which produces a reconstructed image consisting of a matrix of linear attenuation coefficients in a thin slice through the sample. A linear attenuation coefficient reflects the probability per unit length for an $X$ ray to interact as it passes through a material, and is a function of the atomic number and the bulk density of that material and the X-ray energy.

\section{Experimental Process}

A high permeability sample from the oil leg of a sandstone reservoir (porosity was $26.4 \%$ and gas permeability was 15.3 darcies), one inch $(2.54 \mathrm{~cm})$ in diameter and one and one fourth inches (3.18 $\mathrm{cm})$ in length, was uniformly wrapped with Teflon ${ }^{\circledR}$ tape. Plastic endpieces, containing distribution grooves were tapped to fit $1 / 8$ inch $(0.64 \mathrm{~cm})$ pipe fittings and were placed on both ends of the plug. A plastic flow cell was created by molding Bio-plastic ${ }^{\circledR}$ (a liquid casting plastic) in place, around the plug and endpieces. This was allowed to cure for 48 hours. Silicone rubber was used externally to insure no leakage around all connections. The sample (pore volume of $3.49 \mathrm{cc}$ ) was flushed with isooctane, iso-propyl alcohol, methanol and air dried overnight. Prior CT scanning (using a medical CT scanner with resolution of $0.25 \mathrm{~mm} \times 0.25 \mathrm{~mm} \times 3 \mathrm{~mm}$ ) revealed this sample to be relatively uniform. The effective gas permeability of the core plug plus the holder was measured to be 8.14 darcies.

A computed microtomographic apparatus designed and constructed at the National Synchrotron Light Source (NSLS) of Brookhaven National Laboratories (BNL) was utilized for these experiments. This microtomographic apparatus is shown schematically in Figure 1 and is discussed in previous references. An assembly of stepping motor driven translators and rotators were used to move the object through the radiation beam during sampling of the X-ray attenuation. A vertical translator was used to select the slice to be imaged. A horizontal translator was used to move the object through the 
beam while the attenuation was sampled. The flow cell assembly was mounted in the apparatus, as shown in Figure 2.

The CMT apparatus was operated within the shielded hutch at the X17b experimental station. Here, a narrowly colimated high energy X-ray beam produced by a superconducting wiggler was used to image a $6 \mathrm{~mm}$ diameter subsection of the flow cell. Ninety five spatially sequential images were obtained of the dry core within the flow cell. Stepping motors were controlled by a computer with programs automatically placing the moving stages at the correct start position at the conclusion of each slice scan. Spatial resolution of the resulting images was 30 micrometers. Imaging time was approximately 30 minutes per slice.

After the dry rock images were obtained, the flow cell was flushed with $\mathrm{CO}_{2}$ for twenty minutes to minimize trapped gas during the saturation step. The core plug was then flooded with hexadecane doped with iodohexadecane ( $40 \%$ by weight). The oil was then displaced by water and scanned again. Flow was accomplished by gravity feed, from the bottom of the cell, with a constant head of four inches of water. The effluent was measured by weight. The steady state flow rate of water after breakthrough was found to be $0.14 \mathrm{cc} / \mathrm{min}$. The capillary number was calculated to be $4 \times 10^{-7}$ for this displacement. Seventy two spatially sequential slices (resolution of 30 micrometers) were obtained of the same $6 \mathrm{~mm}$ internal subsection of the flow cell following displacement. After reconstruction the microtomographic images were transferred to a Sun $6 / 70$ workstation for visualization and processing.

\section{Experimental Results}

Several microtomographic images which were obtained of the dry sandstone are shown in Figure 3. A three-dimensional volume of the sandstone sample was obtained by stacking together the spatially sequential microtomographic slices. An image, showing the resulting volume data set, with a section removed to reveal the interior, is also shown in Figure 3. The images clearly show pores and structural features not visible with the resolution of conventional medical CT scanners. The average porosity calculated from these microtomographic images was $24.5 \%$.

Several microtomographic images obtained at remaining oil saturation are shown in Figure 4. A three dimensional volume was created by stacking together sequential slices and is shown in Figure 4 . Both oil (white) and brine (black) phases were observable within the imaged rock matrix (gray). Although, measures were taken to clean the core, the aqueous phase appears in the images to behave as a non-wetting phase. Further investigation revealed that the presence of waxy coatings were known to occur in core samples from this area which could result in producing an oil wet core sample. The average water saturation was calculated to be $25.1 \%$. A plot showing the porosity and saturation profiles is provided in Figure 5. A three dimensional view of the water distribution is provided in Figure 6 . Here oil and rock have been rendered transparent, allowing three dimensional visualization of the water saturation. This method for obtaining saturation distributions has clear advantages over earlier woods metal ${ }^{17}$ and other destructivè techniques.

\section{Simulation}

\section{Lattice Boltzmann Simulation}

The lattice-Boltzmann method is a computational fluid dynamics scheme which handles arbitrarily complex boundaries. Thus, it is a particularly attractive method for single and multiphase flow problems in porous media at the pore network level. A detailed description of the method is beyond the scope of this paper. Interested readers are referred elsewhere ${ }^{18-23}$. 
Simulations of the experiment described in the previous section were run using a LB model developed at Los Alamos National Laboratory (LANL) for multiphase flow. The code is based on the model of Chen et al. ${ }^{24}$. Fluid interface behavior is implemented via the formulation of Gunstensen et al. ${ }^{25}$ with modifications as described by Grunau et al. ${ }^{21}$. Validation of this model during development and in applications have shown that hydrodynamic behavior is accurately represented. Estimation of constitutive relationships for multiphase flow in porous media (for example, relative permeability) using CMT data and the LANL lattice Boltzmann simulator has been demonstrated ${ }^{14}$.

During and after the simulations, the LB code is able to provide macroscopic and microscopic information. Fundamental information includes: exact fluid distributions, average fluid saturations, local and averaged velocities, local and averaged pressures and fluid momentà. Bulk constitutive quantities such as permeability and relative permeability are calculated using the information listed above.

The dry rock CMT data were input directly into the LB simulator to provide a binary representation of the three-dimensional pore space geometry. The geometry was padded with four additional planes of pore space at the injection end and an additional plane at the outlet end to accommodate simulation boundary conditions. It was desired not to inject non-wetting phase indiscriminately into all pores at the inlet boundary. The four planes serve as space for redistribution of fluid prior to entry into the pore space. The pore space in the simulator was populated with a wetting fluid. Constant pressure boundary conditions were applied and the simulated flow was allowed to proceed to a steady state single phase flow condition. We computed a permeability of 30 darcies for the subset volume from steady state flow data and Darcy's law. A non-wetting phase was then introduced at the entry plane, while maintaining the same pressure differential. The displacement was allowed to continue until non-wetting phase breakthrough. The capillary number for the simulation at the breakthrough condition was determined to be approximately $5 \times 10^{-5}$.

\section{Network Modeling Simulation}

An alternative to flexible computational fluid dynamics codes to study fluid displacements with complex boundary conditions is a rule-based network model to investigate specific processes of interest. Although the ability to model a wide variety of physical phenomena is lost, network models have potential to be applied to much larger data sets. A network model capable of simulating capillary dominated displacements was described recently in the literature ${ }^{13}$. This network model consists of the application of a few basic rules governing stable interfacial configurations and tests for the existence of mechanistic pathways for pore filling/emptying events within a framework capable of large accounting tasks. The primary drainage portion of the described network model ${ }^{13}$ was used to simulate the introduction of non-wetting phase at the inlet face of the CMT geometry subvolume. This sample showed enormous sensitivity to the uptake of fluid with small changes in pore entry size. ${ }^{15}$ The fluid saturation distribution at a pore entry radius of 75 micrometers was selected for comparison with fluid distributions from the low capillary number experimental displacement and LB simulation.

\section{Comparison}

The experimental, lattice Boltzmann, and network model 3-D fluid distributions were examined for commonality. A number of corresponding cross sectional slices are included in Figure 7. Certainly some discrepancies are evident in fluid placement, but on the whole, agreement is exceptional. The lattice Boltzmann distributions at water breakthrough are highly correlated to the physical experimental slices. The nonwetting phase distribution in network model result, in general, appears to be a subset of the others, indicating that the operating capillary pressure controlling the 
displacement front was possibly only slightly higher than that for a pore entry radius of $75 \mu \mathrm{m}$. This kind of comparison between predicted static equilibrium fluid distributions and those obtained from either displacement simulation or direct experimental observation has ramifications for the measurement and modeling of dynamic capillary pressure.

\section{Summary and Conclusions}

Computed microtomography can provide excellent high resolution two- and three-dimensional pore level images of both dry and saturated core samples. The presence of both oil and water can clearly be identified within the pore space of a rock sample. Pore networks derived from CMT data can serve as valuable representations of reservoir rocks for transport property modeling purposes. Simulation and experimental results have been shown to correlate well. These high resolution images of the fluid filled pore space have not been previously available to researchers and will provide needed data for the development and testing of improved multiphase flow relations and physically correct upscaling methods. Recent improvements in CMT technology ${ }^{15}$ will provide rapid and enhanced visualization of fluids within reservoir core material and allow the capture of the dynamics of fluid transport processes, and the investigation of the effects of such parameters as rock texture, wetting, a third phase and initial saturation conditions on transport.

\section{Acknowledgment}

We would like to thank Mobil Exploration and Producing Technical Center for permission to publish this material. This work at Brookhaven was supported in part by the U.S. Dept. of Energy under Contract DE-AC02-76CH00016. The lattice Boltzmann simulation was performed using the resources located at the Advanced Computing Laboratory of Los Alamos National Laboratory, Los Alamos, NM 87545. Thanks go to R. P. Kehl of Kehlco for assistance in some image processing.

\section{References}

1. Spanne, P. and Rivers, M., "Computerized Microtomography using Synchrotron Radiation from the NSLS", Nucl. Instr. Meth. Phy. Res., 1987, pp 1063-67.

2. Nichols, M.C., Kinney, J. H., Johnson, Q.C., Saroyan, R.A., Bonse, U., Nusshardt, R., and Pahl, R., "Synchrotron Microtomography of Supported Catalysts", Rev. Sci. Inst., 60(7), July, 1989, pp. 2475-77.

3. Jones, K.W., Spanne, P., Webb, S.W., Conner, W.C., Beyerlein, R.A., Reagan, W. J., and Dautzenberg, F.M., "Catalyst Analysis using Synchrotron X-ray Microscopy," Nuc. Inst. Meth. Phy. Res., 1991, pp 427-432.

4. Conner, W.C., Webb, S.W., Spanne, P., and Jones, K.W., "Use of X-ray Microscopy and Synchrotron Microtomography to Characterize Polyethylene Polymerization Particles," Macromolecules, 1990, 20, pp. 4742-47.

5. Flannery, B.P., Deckman, H.W., Roberge, W.G., and D'Amico, K.L., "Three Dimensional X-ray Microtomography", Science, Vol 237, 18 September 1987, pp. 1439-44.

6. Spanne, P., Jones, K. W., Herman, H. and Riggs, W. L., "Measurements of Imperfections in Thermal Spray Coating Using Synchrotron Computed Microtomography," J. Thermal Spray Tech. 1993,2, pp.121-25.

7. Dunsmuir, J. H., Ferguson, S.R., D'Amico, K.L., and Stokes, J.P., "X-Ray Microtomography: A New Tool for the Characterization of Porous Media", Soc. Pet. Eng. 22860, 1991. 
8. Coles, M.E., Spanne, P., Muegge, E.L., and Jones, K.W., "Computed Microtomography of Reservoir Core Samples," SCA9401, Society of Core Analysts Annual Technical Conference, September 1214, 1994.

9. Spanne, P., Thovert, J.F., Jacquin, C.J., Lindquist, W.B., Jones, KW., and Adler, P.M., "Synchrotron Computed Microtomography of Porous Media: Topology and Transports", Physical Review Letters, 73(14) 1994, pp. 2001-4.

10. Buckles, J.J., and Eggert, K.G., "Pore Scale Simulation of Improved Oil Recovery Processes", presented at the Computational Technology Initiative for the Oil and Gas Industry, Sante Fe, New Mexico, June 20-23, 1993.

11. Buckles, J.J., Hazlett, R.D., "Application of Lattice Boltzmann Simulation to Oil Reservoir Engineering", presented at the First International Connection Machine Users Meeting, Sante $\mathrm{Fe}$, February 16-18, 1994.

12. Ferréol, B., and Rothman, D.H., "Lattice-Boltzmann Simulations of Flow Through Fontainebleau Sandstone", Transport in Porous Media 20, 1995, pp. 3-20.

13. Hazlett, R. D., "Simulation of Capillary-Dominated Displacements in Microtomo-graphic Images of Reservoir Rocks", Transport in Porous Media, 20, 1995, pp. 21-35.

14. Buckles, J.J., Hazlett, R.D., Chen, S.Y., Eggert, K.G., Grunau, D.W., and Soll, W.E., "Toward Improved Prediction of Reservoir Flow Performance", Los Alamos Science, n. 22, 1994, pp. 112121.

15. Hazlett, R.D., Coles, M.E., Jones, K.W., Andrews, B., Dowd, B., Siddons, P. and Peskin, A., "Developments in Synchrotron X-Ray Microtomography for Application to Flow in Porous Media.," SCA poster, Society of Core Analysts Annual Technical Conference, September 8-10, 1996.

16. Herman, G.T., Image Reconstruction From Projections, Acedemic Press, 1980.

17 Swanson, B. F., "Visualizing Pores and Non-wetting Phase in Porous Rock", Journal of Petroleum Technology, Jan. 1979, pp. 10-18.

18. Chen, S.Y., Dawson, S.P., Doolen, G.D., Janecky, D.R., and Lawniczak, A., "Lattice Methods and Their Applications to Reacting Systems", Computers \& Chemical Engineering, 1995,19(6-7), pp. 617-646.

19. Rothman, D.H. and Zaleski, S., "Lattice-Gas Models of Phase Separation: Interfaces, Phase Transitions, and Multiphase Flow" Rev. Modern Phys. 66, 1994, pp 1417-1479.

20. Succi, S., Benzi, R., Massaioli, F. A Review of the Lattice Boltzmann Method. International Journal of Modern Physics C-Physics and Computers, 4(2), 1993. pp. 409-415.

21. Grunau, D., Chen, S.Y., and Eggert, K.G., "A Lattice Boltzmann Model for Multiphase Fluid Flows", Physics of Fluids A, 5(10), 1993, pp. 2557-2562.

22. Gunstensen, A.K, and Rothman, D.H., "Lattice-Boltzmann Studies of Immiscible Two-Phase Flow Through Porous Media", Journal of Geophysical Research, 98(B4), 1993, p. 6431-6441.

23. Vaidya, R.N., Hazlett, R.D., Buckles, J.J., Coles, M.E., Grunau, D.W., Chen, S.Y., and Eggert, K.G., "Simulation of Wettability Effects on Displacement Processes by Cellular Automata Methods", Third International Symposium on Evaluation of Reservoir Wettabliity and its Effect on Oil Recovery, September 21-23, 1994.

24. Chen, S.Y., Z. Wang, X.W. Shan, and G.D. Doolen. "Lattice Boltzmann Computational FluidDynamics in Three Dimensions", J. Stat. Phys., 68(3/4), 1992, pp. 379-400. 
25. Gunstensen, A.K., D.H. Rothman, S. Zaleski, and G. Zanetti., "Lattice Boltzmann Model of Immiscible Fluids", Phys. Rev. A., 43(8), 1991, pp. 4320-27.

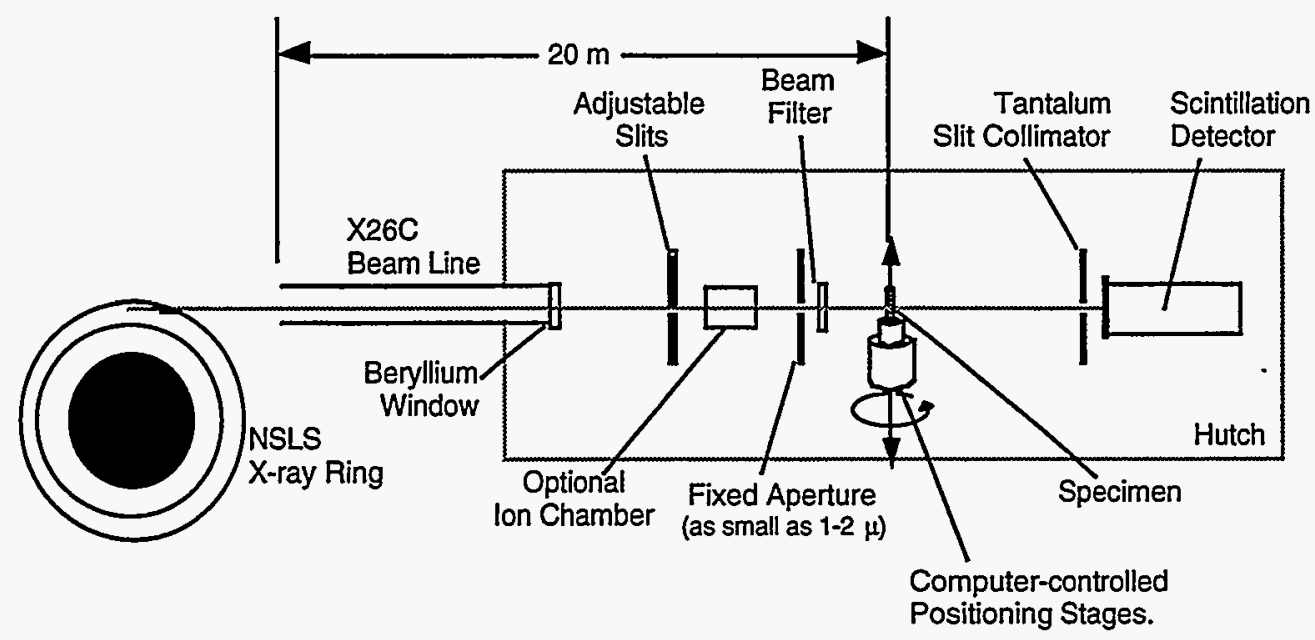

Figure 1: Schematic illustrating microtomographic apparatus. First generation scanning is accomplished by rotating and translating the sample through the X-ray beam. NSLS X-ray ring is not to scale.

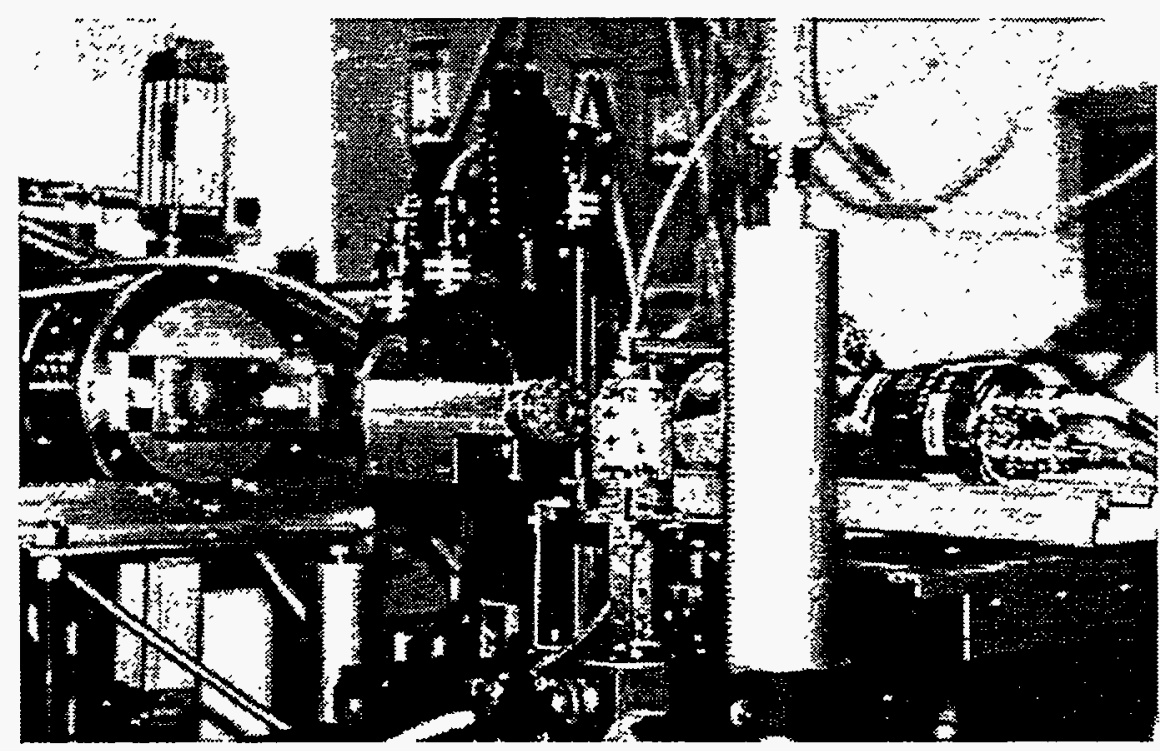

Figure 2: Experimental setup showing flow cell mounted in the CMT apparatus (center). X-rays enter the sample from the right of the picture and are detected by the detector at the left. Rotators and translators, which allow scanning of the sample can be seen at the center bottom of the picture. 

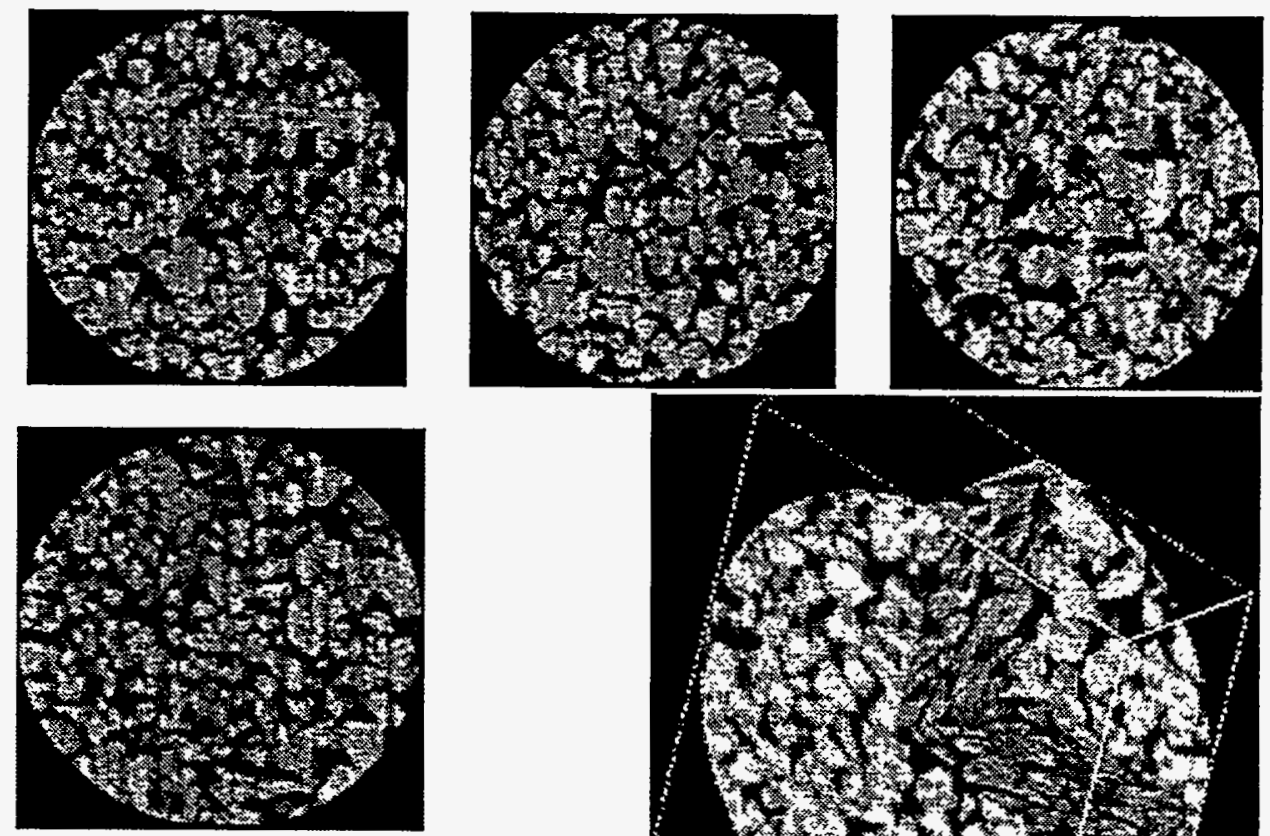

Figure 3: Microtomographic images of dry sandstone. Slice images and volume data set are shown. Resolution was 30 micrometers in all dimensions.
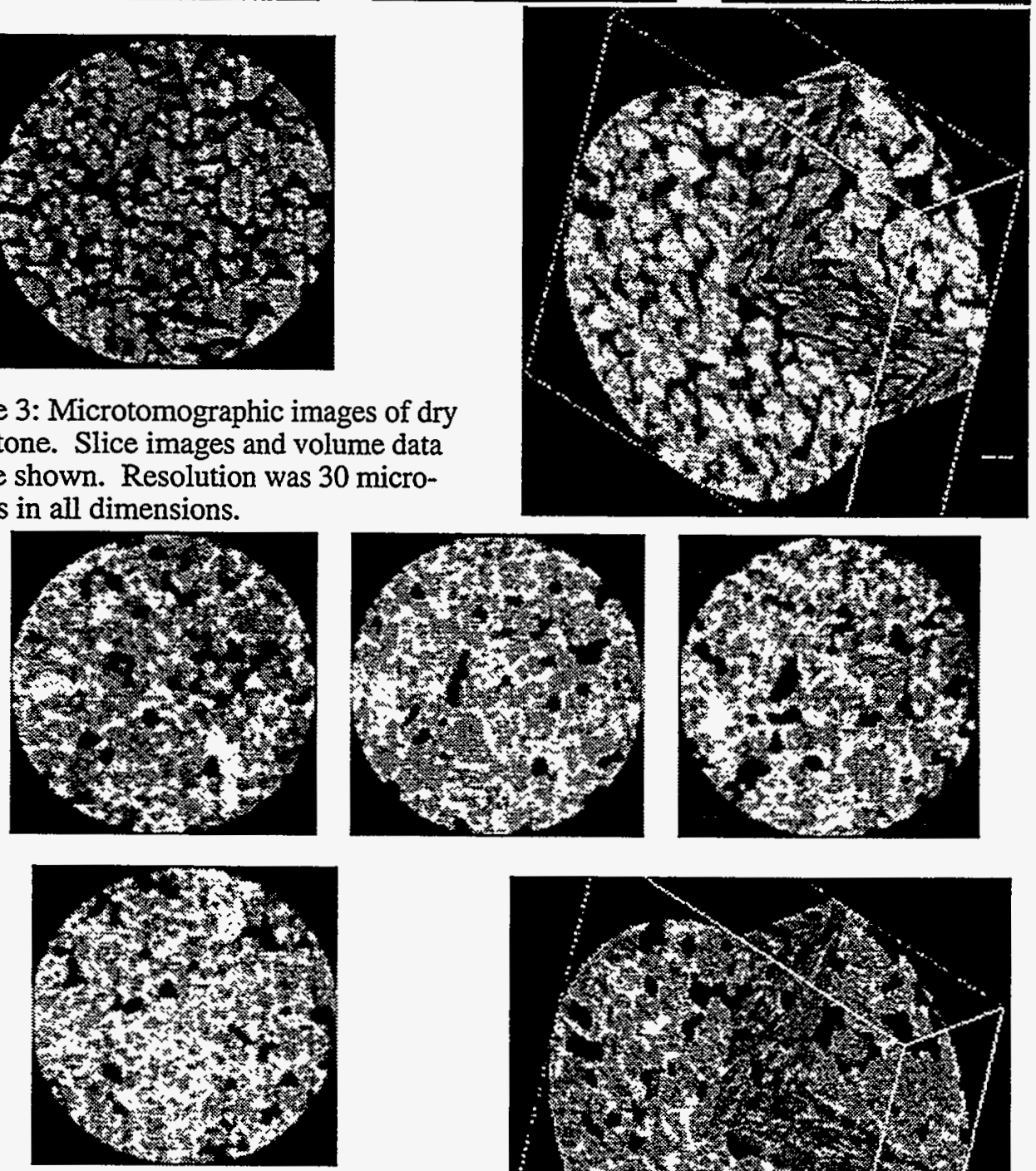

Figure 4: Microtomographic images of sandstone containing oil remaining after flooding with water under capilary controlled conditions. Slice images and volume data set are shown. Resolution was 30 micrometers in

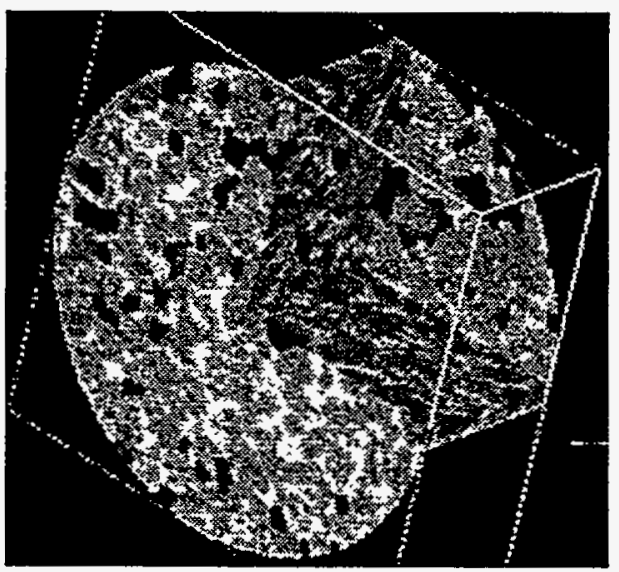
all dimensions. 


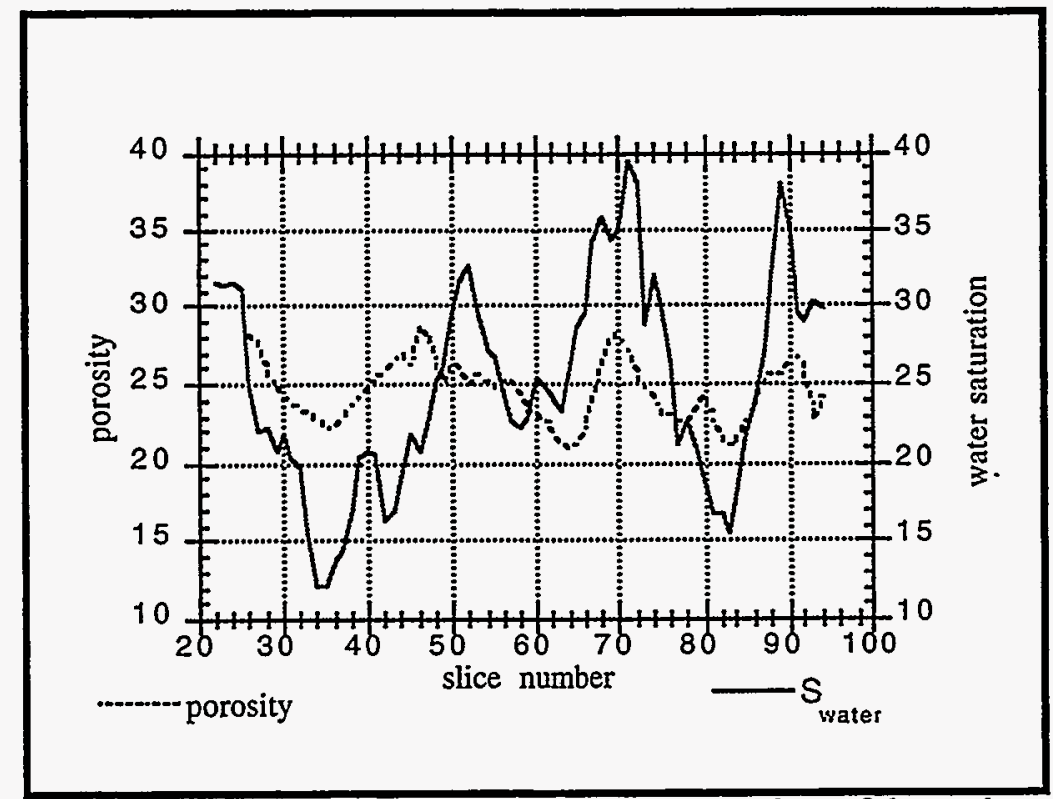

Figure 5: Porosity and saturation profiles from microtomography data of dry and saturated core sample. The average porosity of this $6 \mathrm{~mm}$ subsection (24.5\%) compares to a measured plug porosity of $26.4 \%$. Average water saturation as measured in the slices was calculated to be $25.1 \%$.

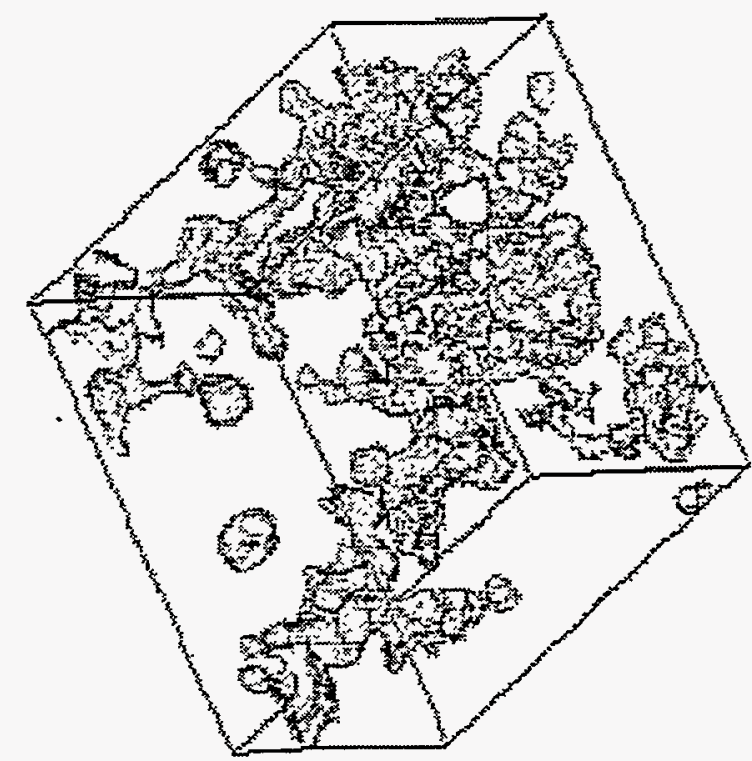

Figure 6. Three dimensional rendering of the water distribution in the core subvolume. The rock and oil-filled pore space have been made transparent. 
(a)
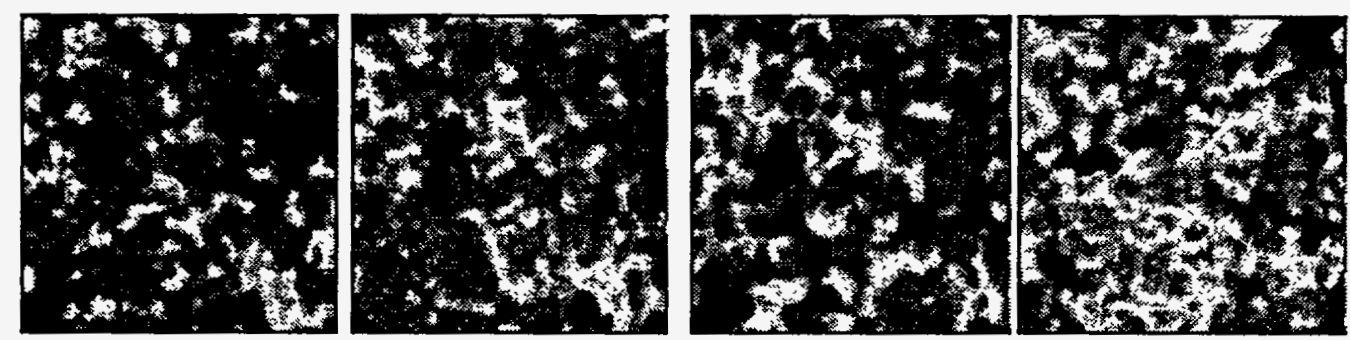

(b)
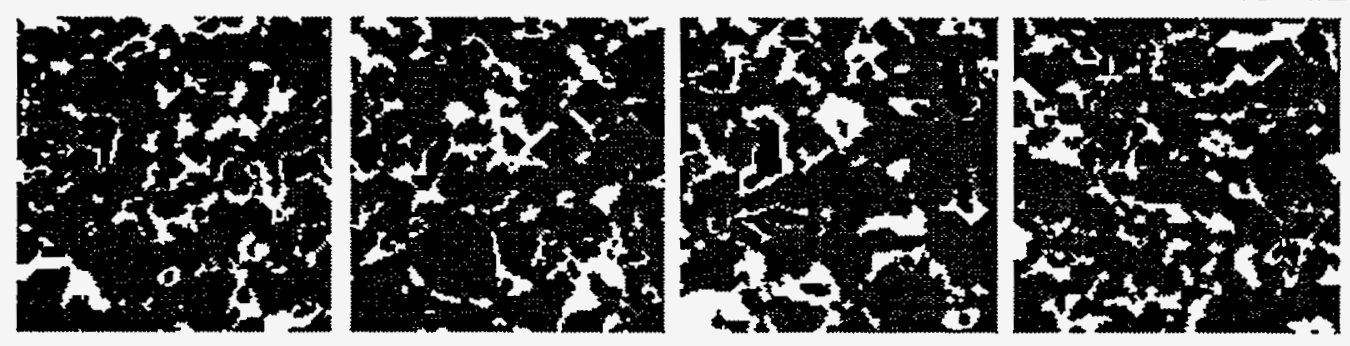

(c)
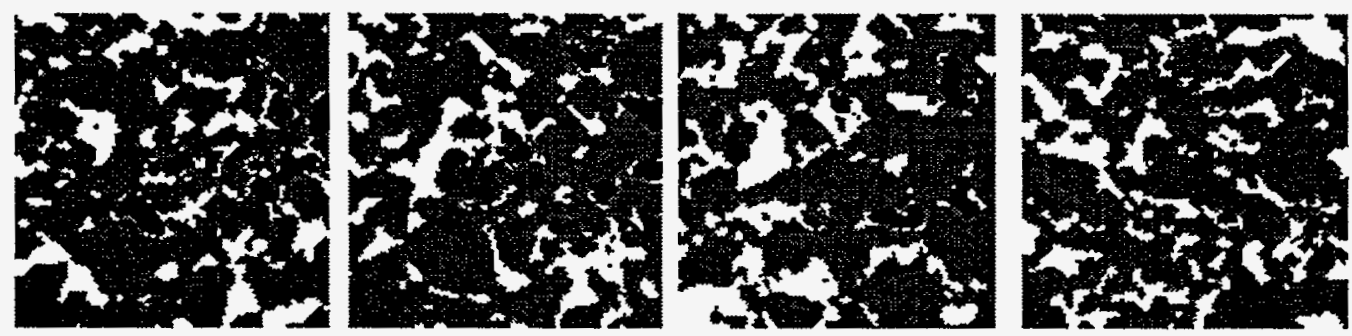

Figure 7: Selected slices showing (a) the experimental results; (b) lattice Boltzmann simulation; and (c) pore network simulation. The images have been cropped to show the center 128 by 128 pixels. Each column reflects the same slice location. Water is shown in black, oil is white and rock is gray. Note the good qualitative agreement between the experimental and simulated results. 